\title{
Cross-Channel Integration and Customer Retention in Omnichannel Retailing: The Role of Retailer Image and Alternative Attractiveness
}

\author{
Ruizhi Li \\ University of Science and Technology of China \\ ruizhili@mail.ustc.edu.cn \\ Hefu Liu \\ University of Science and Technology of China \\ liuhf@ustc.edu.cn
}

\author{
Yang Li \\ University of Science and Technology of China \\ ustcly1@mail.ustc.edu.cn \\ Qian Huang \\ University of Science and Technology of China \\ huangq@ustc.edu.cn
}

\begin{abstract}
Cross-channel integration (CCI) is increasingly considered as an important driver of customer retention in omnichannel retailing. However, the existing findings about the relationship between CCI and customer retention are contradictory, wherein both positive and non-significant findings exist. This study aims to explore the contingency role of retailer image and alternative attractiveness for the above relationship. Specifically, both two-way and three-way interaction effects of retailer image and alternative attractiveness were tested. Our survey finding confirmed the positive relationship between CCI and customer retention. We also found that the positive relationship was negatively moderated by retailer image, while positively moderated by alternative attractiveness. This study further uncovered that alternative attractiveness can weaken the negative moderating effect of retailer image. Implications and limitations of the study are discussed.
\end{abstract}

\section{Introduction}

Facing fiercely competitive retailing environment, contemporary retailers are increasingly devoting to omnichannel strategy in which leveraging on crosschannel integration (CCI) to coordinate different retail channels to serve and retain customers [1]. CCI is intended to improve customers' access to and interaction with online and offline channels during their shopping journeys, through which to enhance customer experience and obtain customer retention [2]. Customer retention is considered a key objective of CCI [3, 4]. However, previous empirical findings regarding how $\mathrm{CCI}$ affects customer retention have been mixed. For example, despite some studies provide the support for the positive influences of CCI [e.g., 5, 6], others indicate that they are insignificant [e.g., 7, 8]. Thus, scholars is calling for more investigations on the potential contingencies in influencing the reactions of customers toward $\mathrm{CCI}$ in omnichannel retailing $[1,9]$.
Exploring the moderating effects of retailer image and alternative attractiveness may help resolve the inconsistency in previous research. Literature on customer behavior has identified the importance of customer marketing factors, especially those both within and outside the retailer, in influencing customer behaviors and decisions[10]. On one hand, both retailer image and alternative attractiveness are found to be key factors that influence customer-retailer relationship and customer retention [11, 12]. For example, retailer image involving customers' positive evaluations, feelings, and attitudes toward a retailer, would lead to strong intentions of customers to remain the relationship with the retailer [13]. Alternative attractiveness represents customers' perception toward the existence and attractiveness of other retailers, which could result in more likelihood to leave the current retailer of customers [14]. One the other hand, both customer judgments toward the retailer and alternative retailers could shape their interaction with marketing operations of the retailer $[15,16]$. They may work together and interactively affect customer retention. For instance, customers may react differently to the same level of CCI to retain within the retailer due to the difference in retailer image and alternative attractiveness. This aligns with previous studies which have reported that retailer image and alternative attractiveness could exert certain influences on reactions of customers toward the retailer's marketing communication [17, 18]. Furthermore, according to Dawson and Richter [19], when the relationship between $\mathrm{CCI}$ and customer retention is contingent on both retailer image and alternative attractiveness, a three-way interaction effect is suggested. However, to the best of our knowledge, few empirical research has been conducted to investigate the interaction effects among CCI, retailer image and alternative attractiveness on customer retention. This void remains a significant research gap.

The current study makes an effort to address the shortfall by answering the following research questions: (1) How does retailer image moderate the relationship between CCI and customer retention; (2) How does 
alternative attractiveness moderate the relationship between CCI and customer retention and (3) Whether and how do retailer image, alternative attractiveness and CCI exert a three-way interaction effect on customer retention. Figure 1 depicts the research model of this study. The findings of this study could assist specify the boundary conditions under which CCI has varying influence on customer retention. Practically, the understanding of such moderating effects can guide retailers to refer to the retailing and marketing conditions in terms of retailer image and alternative attractiveness when deciding whether to adopt CCI strategies.

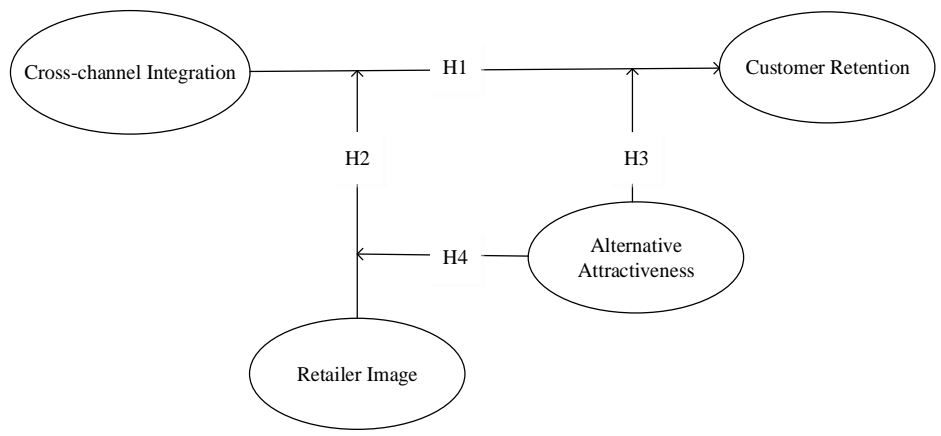

Figure1. Research model

\section{Literature review}

\subsection{Cross-channel integration and customer retention}

Along with the advances in technology and customer demands of seamless and superior experience, omnichannel retailing is becoming increasingly prevalent [1, 2]. It emphasizes the integration and synergy between online and offline retail channels (i.e., CCI). Typically, through CCI, omnichannel retailing enables a cross-channel service system where various channel activities including promotion, transaction information management, product and pricing, information access and order fulfilment, as well as customer service are coordinated [1, p.2]. As a result, customers can simultaneously harness information and functions across all available channels to achieve a seamless experience when shopping [1, 20].

Prior studies have highlighted the significant role of $\mathrm{CCI}$ in omnichannel retailing for customer retention, a key indicator of the success of CCI $[1,3]$. For example, scholars find that CCI can directly and indirectly influence customer retention through improved customer experience with shopping process, retail channels and retailers (e.g., shopping fluency, psychological empowerment, satisfaction, service quality, risk, retailer uncertainty, retailer attractiveness, and switch cost) $[1,6,9,20,21]$. However, some scholars indicate no significant relationship between CCI and customer retention [e.g., 7]. Furthermore, extant literature affirms that customer reaction to $\mathrm{CCI}$ is indeed contextual, which implies that the strength of the influence of CCI on customer retention may be contingent on other factors $[1,22]$. Therefore, it is important to examine the factors that may moderate the relationship between CCI and customer retention.

Prior literature in customer behavior has identified the significance of retailer image and alternative attractiveness for customers' decision on maintaining or leaving relationships with the current retailer [11, 12, 23]. These two factors represent the critical inducement and barrier of customer retention [24]. They provide contexts in which CCI exerts influences on customers. Previous research indicates that such inducement and barrier could change the relative effectiveness, importance and weight of other factors of customer decision [18, 25]. Thus, this study expects that the relationship between CCI and customer retention may be moderated by retailer image and alternative attractiveness.

\subsection{Retailer image}

Retailer image reflects the impression or perception of a retailer that customers hold in mind, deriving from the past experiences and interactions of customers with the retailer [25, 26]. Retailer image is relatively enduring and invariant [27]. It involves customers' overall evaluations of the attractiveness, quality and trustworthiness toward the retailer [13, 28]. Retailers often take substantial time and investments to build a favorable image among consumers, for the significant role of retailer image for remaining customers [29]. With high level of retailer image, customer hold positive attitude toward the retailer and its various offering, thus leading to higher behavior intentions toward the retailer (e.g., purchase, repurchase, loyalty, and retention) [17, $26,30]$. 


\subsection{Alternative attractiveness}

Alternative attractiveness reflects the likely satisfaction available customers perceive other retailers compared to the current retailer [23]. For example, customers perceive that there are many other retailers that can provide good products and services and can satisfy them [31]. It enables the multiple options customers can choose from, thus indicating the intensified competition faced by retailers [18]. Scholars have indicated that customer knowledge about attractive alternatives plays an important role in decision process [18]. A lack of alternative attractiveness may represent a favorable situation for defending and retaining customers [14]. While high alternative attractiveness could motivate customers to switch to other retailers and result in more difficulty for current retailers to retain customers $[32,33]$.

\section{Hypotheses development}

\subsection{Cross-channel integration and customer retention}

Customer retention involves a customer's loyalty and commitment toward a retailer reflected in repurchase intention. It represents the perceptions of customers that they want to continue the existing relationship with the retailer [34]. Extant literature indicates that as a marketing effort and investment, CCI would bring about relationship maintenance $[1,35]$. CCI offers numerous advantages that assist acquire customer retention[36]. Specifically, CCI represents retailers' marketing efforts in improving customer experience through integrating information, price, knowledge and functions across different touchpoints and channels [20]. It could lead to customer retention by satisfying customers' emerging specific shopping needs (e.g., cross-channel information, fulfilment and service) [37]. Additionally, such integrated service package implies high service quality and great convenience, as multiple channels are leveraged simultaneously to service customers and provide necessary information, functions, options and freedoms for customers, which attract customers to retain $[1,20]$. Furthermore, CCI enabling information transparency across multiple channels, could increase customer confidence and prevent customers' misunderstandings and thus promote customer retention [38]. Besides, CCI enables retailers to construct consumption records and files of customers to better understand their preferences and needs, which in turn could contribute to customer retention through personalized services $[1,22]$.

Hypothesis 1 . CCI is positively related to customer retention.

\subsection{Moderating effects of retailer image and alternative attractiveness}

Previous research show that customers' decision making process may associate with their judgment and attitude toward the retailer [17]. For example, favorable retailer image would develop a ceiling effect that may limit the additional value of other marketing activities such as CCI [39]. Accordingly, it can be predicted that retailer image would weaken the effect of CCI on customer retention. However, previous research suggests that customers' positive cognitions toward the retailer would lead to more positive acceptance and appraisal of a given level of the marketing efforts of the retailer[40]. Besides, positive retailer image could enhance customer confidence to interact with different channels and encourage customers to shop through different channels, which lead to a higher efficiency of $\mathrm{CCI}$ and thus the transformation of CCI to customer retention. As such, there seems to be two opposite directions of the moderating role of retailer image. Therefore, the empirical test of it is of both theoretical and practical significance.

This study predicts that customer perceived retailer image would play an important role in affecting how customer react to CCI. Retailer image captures customers' relatively stable evaluation of the retailer based on past experience [27, 29]. High (low) retailer image signify directly and clearly that customers like (dislike) and positively (negatively) appraise the retailer [28]. Customers tend to rely on retailer image to easily ease confusion and accelerate decision making, which may decrease the effect of other decision factors (e.g., CCI)[39]. For example, when retailer image is high, customers present great favorable preference and behavioral intention toward the retailer, which could reduce the importance and value of CCI for customer retention. By contrast, when retailer image is low, purchase from the retailer is reluctant[41]. CCI therefore assumes considerable value to offset the unfavorable conditions deriving from low retailer image by offering ample advantages for customers [1,39].

Hypothesis 2. Retailer image negatively moderates the relationship between $\mathrm{CCI}$ and customer retention.

Similarly, two competing processes predicting the moderating effect of alternative attractiveness on the relationship between CCI and customer retention seem work. On one hand, alternative attractiveness signifies the appeal of competitive retailer for customers, which enhance the likelihood of their switch behavior during their interaction with different channels of focal retailers 
$[32,33]$. This would threat the efficiency of CCI, suggesting the negative moderating effect of alternative attractiveness. However, on the other hand, alternative attractiveness enables the multiple options customers can choose from, which induces the complexity for customers to make decisions (e.g., retention) and is more conducive to the impact of external cues such as CCI [18]. Following this line of thought, CCI would be more influential on customer retention when alternative attractiveness is high.

This study predicts that alternative attractiveness could influence the relationship between CCI and customer retention due to it alters the relative salience of CCI to customer decision (i.e., retention). High level of alternative attractiveness signifies intensive competition and adverse context for retailers to remain customers as customers have extra satisfying retailers to choose from [42]. Under this condition, CCI that aims to engage and retain customer through multiple benefits offering is expected to be more valued and needed [9]. Indeed, it is the increasingly highly competition in retailing that promote retailers to implement omnichannel retailing strategies and CCI to retain customers [4]. However, when customers' perception of alternative attractiveness is low, they would maintain the current relationship no matter the level of customer experience, as they have limited choice [14]. As a result, CCI that enables superior customer experience becomes less significant for customers to make decisions when alternative attractiveness is low versus high. Previous empirical studies have also demonstrated that the role of determinants of customer retention (e.g., satisfaction) is weaker when alternative attractiveness is low [18, 24].

Hypothesis 3. Alternative attractiveness positively moderates the relationship between CCI and customer retention.

We further expect a three-way interaction effect among CCI, retailer image and alternative attractiveness, in which the strength of the moderating effect of retailer image on CCI may be contingent on the level of alternative attractiveness. As we discussed above, the importance of CCI for customer retention would be enhanced by alternative attractiveness. In this condition, even when retailer image is high, CCI may be still

Table 1. Demographics of respondents $(N=261)$

\begin{tabular}{lll}
\multicolumn{3}{c}{ Table 1. Demographics of respondents $(\mathrm{N}=261)$} \\
\hline Characteristic & No. of Respondents & Percentage \\
\hline Gender & 98 & 37.5 \\
Male & 163 & 62.5 \\
Female & & \\
Age & 101 & 38.7 \\
$18-29$ & 131 & 50.2 \\
$30-39$ & 20 & 7.7 \\
$40-49$ & &
\end{tabular}

relevant for customer retention. That is, alternative attractiveness could buffer the reduced value of CCI brought by retailer image. By contrast, low alternative attractiveness induces limited role of CCI, under which retailer image would have greater negative moderating effect on CCI.

Hypothesis 4. Alternative attractiveness weakens the moderating effect of retailer image on the relationship between CCI and customer retention.

\section{Methodology}

\subsection{Data collection}

This study collected data using an online survey method where a professional survey platform in China called Sojump [http://www.sojump.com] hosted the web-based questionnaire. In specific, we conducted the survey in cooperation with an online market research company. The questionnaires were electronically distributed by the company. The definition of omnichannel retailers was firstly presented to potential respondents in the survey questionnaire. Thereafter, a question that inquired respondents whether they had purchased from an omnichannel retailer was inserted. Only respondents who answered yes were permitted to enter the following questions after filling in the name of the retailer. A total of 320 responses were yielded in around two weeks. Among them, 59 responses were deleted as the key questions were not answered or they were completed under the minimum baseline for time of 5 min. Finally, a sample of 261 data points were used for analysis. The sample contains retailers in many industries, such as closing (e.g., Uniqlo), shoes (e.g., Nike), electrical equipment and electronic consumer goods (e.g., Gome), supermarket (e.g., Carrefour), etc. Table 1 depicts the demographics of the sample.

To detect the potential non-response bias, a t-test that compared the responses on focal variables between the early (i.e., first 25\%) and late (i.e., final 25\%) samples was conducted. The comparison indicates no significant difference, suggesting that non-response bias is unlikely to be a threat in this study. 


\begin{tabular}{lll}
$>=50$ & 9 & 3.4 \\
Education & & \\
High school or below & 9 & 3.4 \\
Junior college & 35 & 13.4 \\
Bachelor & 184 & 70.5 \\
Master or above & 33 & 12.6 \\
Personal income & & \\
$<=1000$ & 15 & 5.7 \\
$1001-2000$ & 16 & 6.1 \\
$2001-4000$ & 36 & 13.8 \\
$4001-5000$ & 78 & 29.9 \\
$>5000$ & 116 & 44.4 \\
\hline
\end{tabular}

\subsection{Measurement}

The measurement items of this study were derived from previously validated measures, with scales ranging from 1 (strongly disagree) to 5 (strongly agree) in the perspective of customers. Specifically, ten items of CCI were adapted from Oh, Teo and Sambamurthy [35], which captured the degree that a customer perceived a retailer integrates various information and functions between its online and offline retail channels, including promotion, information access, product and pricing information management, transaction information, order fulfilment, as well as after-sale services. Four items were adapted from Jones, Mothersbaugh and Beatty [31] to measure alternative attractiveness. Three items for retailer image were adapted from Sääksjärvi and Samiee [28]. Four items were adapted from Bojei, Julian, Wel and Ahmed [43] to measure customer retention. Appendix A presents the measurement items of this study.

\section{Results}

\subsection{Common method bias}

Common method bias was first evaluated using Harman's one-factor test. The results indicated four factors with eigenvalues above 1.0 and accounted for $59.46 \%$ of the total variance. The first factor did not account for most of the variance $(18.38 \%)$. The fit between the one-factor model and the measurement model was further compared via LISREL. Results revealed that the fit of the one-factor model $\left(\chi^{2}=\right.$ 1497.704 on d.f. $=189$, RMSEA $=0.163, \mathrm{CFI}=0.801$, $\mathrm{IFI}=0.802, \mathrm{NFI}=0.772, \mathrm{NNFI}=0.779)$ was considerably worse $(\mathrm{p}<0.01)$ than that of the measurement model of the current study $(\chi 2=460.809$ on d.f. $=183, \mathrm{RMSEA}=0.076, \mathrm{CFI}=0.948, \mathrm{IFI}=0.948$, $\mathrm{NFI}=0.914$, NNFI $=0.940)$. Therefore, the common method bias is not a serious issue in this study.

\subsection{Measurement model}

This study employed SPSS19.0 to evaluate the validity and reliability of the measurement model. In table 2, loadings of all items are above the criterion of 0.6 and scores for AVEs of all constructs are greater than the benchmark value of 0.50. Estimates of Cronbach's Alpha and composite reliability are higher than the benchmark value of 0.70 . These results indicate a favorable convergent validity and reliability of the measurement model of this study. In table 3 , the square root of the AVEs for each construct is higher than its correlations with other constructs, thereby indicating a satisfactory discriminant validity of the measurement model.

Moreover, a multicollinearity test was conducted. Prior scholars suggest that multicollinearity exists when the variance inflation factors (VIFs) are higher than 10 or when tolerance values are lower than 0.1 . The results reveal that the highest VIF is 1.570 and the lowest tolerance value is 0.637 . Thus, multicollinearity is unlikely to be a significant problem in this study.

Table 2. Results of confirmatory factor analysis

\begin{tabular}{llllll}
\hline Constructs & Items & Loadings & $\begin{array}{l}\text { Composite } \\
\text { Reliability }\end{array}$ & $\begin{array}{l}\text { Cronbach's } \\
\text { Alpha }\end{array}$ & AVE \\
\hline CCI & 10 & $0.646-0.794$ & 0.914 & 0.895 & 0.516 \\
Retailer image & 3 & $0.778-0.817$ & 0.842 & 0.718 & 0.640 \\
Alternative Attractiveness & 4 & $0.807-0.851$ & 0.899 & 0.849 & 0.689 \\
Customer Retention & 4 & $0.670-0.784$ & 0.833 & 0.732 & 0.556 \\
\hline
\end{tabular}

Note: $\mathrm{AVE}=$ average variance extracted

Table 3. Means, standard deviations, and correlations

\begin{tabular}{lllllllll}
\hline Constructs & Mean & S.D. & 1 & 2 & 3 & 4 & 5 & 6 \\
\hline CCI & 3.68 & 0.72 & $\mathbf{0 . 7 1 8}$ & & & & \\
Retailer image & 4.04 & 0.62 & $0.322^{* *}$ & $\mathbf{0 . 8 0 0}$ & & &
\end{tabular}




\begin{tabular}{lllllllll} 
Alternative attractiveness & 3.23 & 0.74 & -0.113 & -0.113 & $\mathbf{0 . 8 3 0}$ & & & \\
Customer retention & 3.77 & 0.63 & $0.452^{* *}$ & $0.531^{* *}$ & $-0.216^{* *}$ & $\mathbf{0 . 7 4 6}$ & & \\
Age & - & - & 0.049 & 0.023 & -0.018 & 0.062 & - \\
Gender & - & - & 0.078 & 0.109 & -0.027 & $0.206^{* *}$ & $-0.154^{*}$ & - \\
\hline
\end{tabular}

Note: The diagonal row shows the square root of AVE; * $\mathrm{p}<0.05 ; * * \mathrm{p}<0.01$

\subsection{Structural model}

Hierarchical regression analyses were used to test the hypotheses. Results were shown in table 4 . As predicted in $\mathrm{H} 1$, results in model 2 suggest that $\mathrm{CCI}$ is positively related to customer retention $(\beta=0.304, \mathrm{p}<0.001)$. Furthermore, results in model 3 indicate that the relationship between CCI and customer retention is negatively moderated by retailer image $(\beta=-0.244$, $p<$ 0.001 ) while positively moderated by alternative attractiveness $(\beta=0.128, p<0.05)$. Thus, $\mathrm{H} 2$ and $\mathrm{H} 3$ are supported. Figure 2 and 3 further illustrate the moderating effect of retailer image and alternative attractiveness, respectively. Results in model 4 indicate a significant three-way interaction among CCI, retailer image and alternative attractiveness $(\beta=0.211, p<0.05)$. Figure 4 shows that when alternative attractiveness is low, retailer image negatively influences the relationship between CCI and customer retention. However, when alternative attractiveness is high, the influence of retailer image on the relationship between CCI and customer retention becomes extremely weak, as the positive relationship between CCI and customer retention appears no significant change under the condition of high versus low retailer image. This indicates that alternative attractiveness reduces the negative moderating effect of retailer image on the link between $\mathrm{CCI}$ and customer retention, thus supporting $\mathrm{H} 4$.

Table 4. Results of hierarchical regression analysis

\begin{tabular}{lllll}
\hline & Model 1 & Model 2 & Model 3 & Model 4 \\
\hline Age & 0.072 & 0.043 & 0.065 & 0.061 \\
Gender & $0.162 * * *$ & $0.106 * *$ & $0.111^{* *}$ & $0.104 * *$ \\
CCI & & $0.304 * * *$ & $0.358^{* * *}$ & $0.369^{* * *}$ \\
Retailer image (RI) & & $0.383 * * *$ & $0.357 * * *$ & $0.352^{* * *}$ \\
Alternative attractiveness (AA) & & $-0.118^{* *}$ & $-0.124 * *$ & $-0.131^{* *}$ \\
RI*CCI & & & $-0.244 * * *$ & $-0.225^{* *}$ \\
AA*CCI & & & $0.128^{*}$ & 0.036 \\
RI*AA & & & -0.088 & -0.097 \\
CCI*RI*AA & & & & $0.211^{*}$ \\
$\mathrm{R}^{2}$ & 0.051 & 0.409 & 0.458 & 0.471 \\
Adjusted R & 0.044 & 0.397 & 0.441 & 0.452 \\
F Change & $6.992 * *$ & $51.435 * * *$ & $7.555^{* * *}$ & $6.209 *$ \\
\hline
\end{tabular}

Note: $* \mathrm{p}<0.05 ; * * \mathrm{p}<0.01 ; * * * \mathrm{P}<0.001$

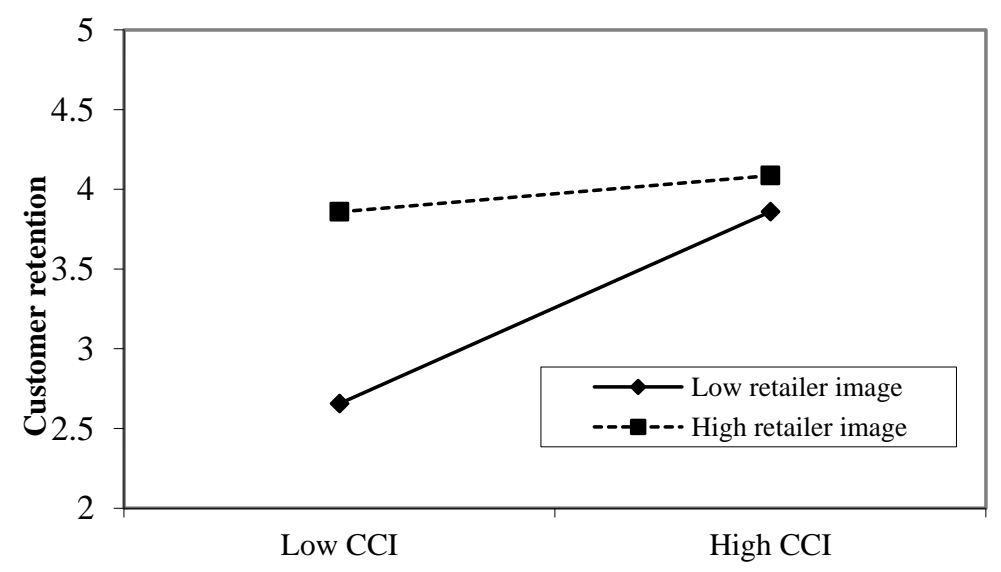

Figure 2. Moderating effect of retailer image 


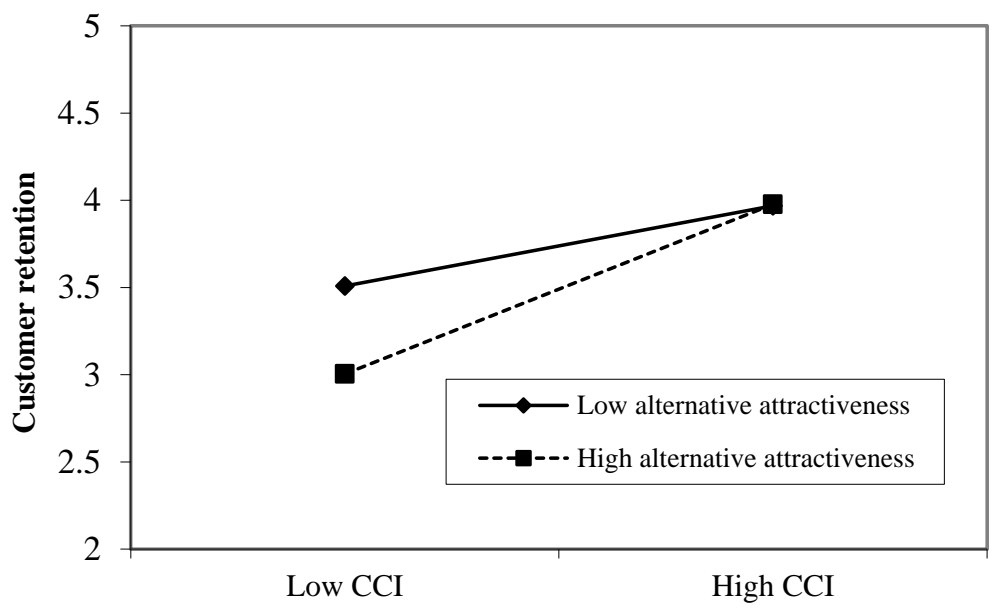

Figure 3. Moderating effect of alternative attractiveness

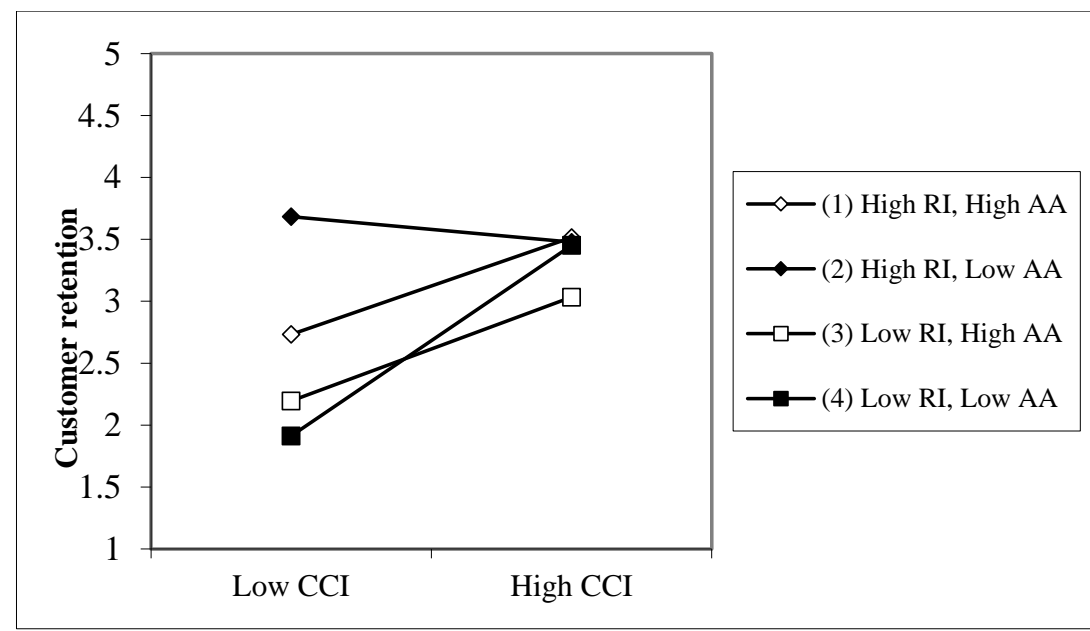

Figure 4. Three-way interaction among $\mathrm{CCl}$, retailer image and alternative attractiveness

Although we have incorporated age and gender as control variables, there are other omitted variables that may cause endogeneity and influence the results of this study. To address the possible endogeneity issue, we performed an endogeneity test following the two step econometric procedure proposed by Heckman [44]. In the first step, we created a dummy variable indicating the high (i.e., above the median) or low (i.e., below or equal to the median) level of CCI. We then computed the LAMBDA (i.e., the inverse Mill's ratio) using SPSS based on a probit model by regressing the above dummy variable on gender and age. In the second step, we added the lambda variable as the additional control variable, along with CCI, age and gender to predict customer retention. Findings indicate that the relationship between the lambda variable and the dependent variable is statistically insignificant $(\beta=0.149, \mathrm{t}=0.620)$, which indicates endogeneity is not a threat.

\section{Discussion}

Consistent with previous studies [e.g., 6], this study finds support for the positive relationship between CCI and customer retention. This finding affirms the potential benefit for relationship maintenance with current customers by implementing omnichannel strategy to satisfy customer demands of seamless experience, convenience, control and safety, among others $[1,20]$.

This study further reveals the negative moderating effect of retailer image and positive moderating effect of alternative attractiveness on the influence of marketing mix and efforts (i.e., CCI) on customer outcome (i.e., customer retention). These findings are similar to prior studies, which assert that customers' positive evaluation of the focal retailer (i.e., retailer image) and alternative retailers (i.e., alternative attractiveness) offer positive 
and negative conditions for their relationship continue intention with the focal retailer, respectively, therefore altering the relative salience and effects of other factors $[18,25]$. That is, high retailer image limits while high alternative attractiveness adds the importance and influence of CCI on customer retention.

This study also examines the three-way interaction effect among CCI, retailer image and alternative attractiveness, in which we predict the moderating effect of retailer image on the relationship between CCI and customer retention is contingent on the level of alternative attractiveness. In line with the prediction, the findings indicate that alternative attractiveness assures the significance of CCI, in which retailer image could exert limited negative influence on the role of CCI. That is to say, when alternative attractiveness is high, CCI is positively related to customer retention no matter of the level of retailer image. However, when alternative attractiveness is low, customers have less difficulty to make retention decisions, in which CCI only has a significant influence on customer retention when retailer image is low.

\section{Implications and limitations}

\subsection{Theoretical and practical implications}

The current study sheds light on the literature on CCI in omnichannel retailing. This study reveals the significant two-way interaction effects between CCI and retailer image, as well as between CCI and alternative attractiveness. The findings confirm that retailer image negatively moderates while alternative attractiveness positively moderates the relationship between CCI and customer retention. Ignoring the contexts of retailer image and alternative attractiveness would hinder the complete understanding of the role of CCI for customers. The results thus address the research call for identifying important moderating conditions for the influence of CCI on customer behavior. Herhausen, Binder, Schoegel and Herrmann [9] and Li, Liu, Lim, Goh, Yang and Lee [1] have pointed out that more attention should be paid on potential factors that may moderate customer reactions toward CCI. This study thus advances the understanding on the conditional effects of CCI by specifying customer cognition toward the focal and competitive retailers, i.e., retailer image and alternative attractiveness, as important boundary conditions to examine how CCI influences customer retention. As a result, this study offers a plausible explanation to prior inconsistent findings regarding the link between CCI and customer retention $[1,7]$. The results indicate that CCI may exert considerable influence on customer retention when retailer image is relatively low or when alternative attractiveness is relatively high. However, when retailer image is high or when alternative attractiveness is low, customers already have strong intentions to retain, under which conditions the value and role of CCI for customer retention is restricted.

Another contribution of this study lies in the threeway interaction effect among CCI, retailer image and alternative attractiveness, which notes that the two-way interaction effect between CCI and retailer image is indeed contextual on alternative attractiveness. Even in high retailer image context, CCI can contribute to customer retention, only when alternative attractiveness is high. It highlights the necessary extra-firm boundary condition (i.e., alternative attractiveness) to fully make CCI work for customer retention, which is especially the case when retailer image is high. Although CCI provides opportunity for customer retention, the importance of CCI may lost in a high retailer image condition, as retailer image increases customer retention decision. However, CCI can still be relevant and important when it encounters high alternative attractiveness. This significant three-way interaction effect provides us a deep understanding of the effect of CCI, which is contingent on the joint influence of retailer image and alternative attractiveness.

The findings of this study also offer managerial implications for retailers in implementing omnichannel strategy. This study recommends to retailers that despite it remains important to retain customer through CCI, they should strategically invest resources and efforts in CCI according to the level of retailer image and alternative attractiveness. A huge investment in CCI will not always be effective in improved customer retention. For example, figure 2 and 3 show that when retailer image is high or alternative attractiveness is low, an increase in CCI has only minor influence on a customer's retention. Therefore, retailers should tailor their CCI investment with customers' perception of retailer image and alternative attractiveness. Retailers could survey their customers in advance to assess their perceived retailer image and alternative attractiveness. When alternative attractiveness is high, retailers should devote more efforts to implementing CCI, due to in such condition CCI is effective in improving customer retention as figure 3 and 4 shown. Alternatively, when alternative attractiveness is low, retailer should commit to CCI investment, only when retailer image is low. In this condition, CCI is positively related to customer retention. However, when alternative attractiveness is low and retailer image is high, retailers should save the CCI cost, for it is not as crucial as it is elsewhere.

\subsection{Limitations and future research}

This study has several limitations that can be addressed by further research. First, this study relied on 
perceptual data of 261 respondents to yield results. Although the analytical results indicate that the potential biases are not significant issues in this study, future research could validate our research framework based on a larger survey sample or objective data. Second, this study collected data only in China, which may limit the generalizations of the findings. We suggest scholars to further conduct research in different countries and culture to test the applicability of our results. Third, this study recruited respondents from active online customers, which may cause self-selection bias. Although customers in omnichannel retailing are indeed online customers, researchers can further recruit customers in physical stores to enrich the sample. Fourth, we cannot deny that there are still other factors that may alter the influence of CCI. To extend the scope of this study, future research could further explore the moderating role of customer characteristic (e.g., personality, shopping habit and orientations), retailer types (e.g., online channel first or offline channel first retailers), or market factors (e.g., market concentration), among others, when researching the effect of CCI on customer. Lastly, the sample of this study involves various industries. The importance and effectiveness of omnichannel strategies for different industries may vary due to the differences in product categories and customer behavior patterns [45]. Future research could differentiate to different researches by comparing the industries and respective results and examine whether the industrial focus has an influence on the outcome.

\section{Appendix A}

Cross-Channel Integration (CCI)

CCI1: The Website highlights in-store promotions that are taking place in the physical store

CCI2: The Website advertises the physical store by providing address and contact information of the physical store.

CCI3: The Website allows customers to search for products available in the physical store.

CCI4: The firm allows checking of inventory status at the physical store through the Website.

CCI5: The physical store allows customers to self-collect their online purchases.

CCI6: The firm allows customers to choose any physical store from which to pick up their online purchases.

CCI7: The firm maintains integrated purchase history of customers' online and offline purchases.

CCI8: The firm allows customers to access their prior integrated purchase history.

CCI9: The in-store customer service center accepts return, repair or exchange of products purchased online.

CCI10: The Website provides post-purchase services such as support for products purchased at physical stores

Retailer image (RI)

RI1: The retailer has an attractive image.

RI2: The retailer is a first-class, high-quality company.

RI3: I trust the retailer

Alternative Attractiveness

AA1: If I need to change retailers, there are other good retailers to choose from.

AA2: I would probably be happy with the products and services of another retailer.

AA3: Compared to this retailer, there are other retailers with which I would probably be equally or more satisfied.

AA4: Compared to this retailer, there are many other retailers with whom I could be satisfied.

Customer Retention (CR)

CR1: I feel loyalty towards this store

CR2: I think of myself as a loyal customer to this store

CR3: I would rather stay with the store I usually frequent than trying a different store I am unsure of

CR4: I prefer to shop frequently at one store only

\section{Reference}

[1] Y. Li, H. Liu, E.T.K. Lim, J.M. Goh, F. Yang, M.K.O. Lee, Customer's reaction to cross-channel integration in omnichannel retailing: The mediating roles of retailer uncertainty, identity attractiveness, and switching costs, Decision Support Systems, 109 (2018) 50-60.

[2] Y. Chen, C.M.K. Cheung, C.-W. Tan, Omnichannel business research: Opportunities and challenges, Decision Support Systems, 109 (2018) 1-4.

[3] E. Bendoly, J.D. Blocher, K.M. Bretthauer, S. Krishnan, M.A. Venkataramanan, Online/In-Store Integration and Customer Retention, Journal of Service Research, 7 (2005) 313-327.

[4] D.R. Bell, S. Gallino, A. Moreno, How to win in an omnichannel world, MIT Sloan Management Review, 56 (2014) 45-53.

[5] S. Van Baal, Should retailers harmonize marketing variables across their distribution channels? An investigation of cross-channel effects in multi-channel retailing, Journal of Retailing and Consumer Services, 21 (2014) 1038-1046.

[6] M. Frasquet, M.-J. Miquel, Do channel integration efforts pay-off in terms of online and offline customer loyalty?, International Journal of Retail \& Distribution Management, 45 (2017) 859-873.

[7] H.-C. Chiu, Y.-C. Hsieh, J. Roan, K.-J. Tseng, J.-K. Hsieh, The challenge for multichannel services: Cross-channel freeriding behavior, Electronic Commerce Research and Applications, 10 (2011) 268-277.

[8] H.-H. Lee, J. Kim, Investigating dimensionality of multichannel retailer's cross-channel integration practices and effectiveness: shopping orientation and loyalty intention, Journal of Marketing Channels, 17 (2010) 281-312.

[9] D. Herhausen, J. Binder, M. Schoegel, A. Herrmann, Integrating bricks with clicks: retailer-level and channel-level outcomes of online-offline channel integration, Journal of retailing, 91 (2015) 309-325.

[10] V.G. Hariharan, K.K. Desai, D. Talukdar, J.J. Inman, Shopper marketing moderators of the brand equity - behavioral loyalty relationship, Journal of Business Research, 85 (2018) 91-104.

[11] A. Hunneman, P.C. Verhoef, L.M. Sloot, The moderating role of shopping trip type in store satisfaction formation, Journal of Business Research, 78 (2017) 133-142.

[12] S.H.-W. Chuah, M. Marimuthu, J. Kandampully, A. Bilgihan, What drives Gen Y loyalty? Understanding the mediated moderating roles of switching costs and alternative attractiveness in the value-satisfaction-loyalty chain, Journal of Retailing and Consumer Services, 36 (2017) 124-136.

[13] J.C. Suh, Y. Youjae, When brand attitudes affect the 
customer satisfaction-loyalty relation: the moderating role of product involvement, J Consum Psychol, 16 (2006) 145-155. [14] I.C. Chang, C.C. Liu, K.C. Chen, The push, pull and mooring effects in virtual migration for social networking sites, Inform Syst J, 24 (2014) 323-346.

[15] M.W. Nyadzayo, S. Khajehzadeh, The antecedents of customer loyalty: A moderated mediation model of customer relationship management quality and brand image, Journal of Retailing and Consumer Services, 30 (2016) 262-270.

[16] E. Ghazali, B. Nguyen, D.S. Mutum, A.A. Mohd-Any, Constructing online switching barriers: examining the effects of switching costs and alternative attractiveness on e-store loyalty in online pure-play retailers, Electronic Markets, 26 (2016) 157-171.

[17] A.-T. Hsieh, C.-K. Li, The moderating effect of brand image on public relations perception and customer loyalty, Marketing Intelligence \& Planning, 26 (2008) 26-42.

[18] C.-Y. Li, Switching barriers and customer retention: Why customers dissatisfied with online service recovery remain loyal, Journal of Service Theory and Practice, 25 (2015) 370393.

[19] J.F. Dawson, A.W. Richter, Probing three-way interactions in moderated multiple regression: development and application of a slope difference test, Journal of Applied Psychology, 91 (2006) 917.

[20] M. Zhang, C. Ren, G.A. Wang, Z. He, The impact of channel integration on consumer responses in omni-channel retailing: The mediating effect of consumer empowerment, Electronic Commerce Research and Applications, 28 (2018) 181-193.

[21] X.L. Shen, Y.J. Li, Y.Q. Sun, N. Wang, Channel integration quality, perceived fluency and omnichannel service usage: The moderating roles of internal and external usage experience, Decision Support Systems, 109 (2018) 61-73.

[22] P.C. Verhoef, P. Kannan, J.J. Inman, From multi-channel retailing to omni-channel retailing: introduction to the special issue on multi-channel retailing, Journal of retailing, 91 (2015) 174-181.

[23] H.H. Chang, K.H. Wong, S.Y. Li, Applying push-pullmooring to investigate channel switching behaviors: Mshopping self-efficacy and switching costs as moderators, Electronic Commerce Research and Applications, 24 (2017) 50-67.

[24] S.H.-W. Chuah, P.A. Rauschnabel, M. Marimuthu, R. Thurasamy, B. Nguyen, Why do satisfied customers defect? A closer look at the simultaneous effects of switching barriers and inducements on customer loyalty, Journal of Service Theory and Practice, 27 (2017) 616-641.

[25] Z. Shou, R. Guo, Q. Zhang, C. Su, The many faces of trust and guanxi behavior: Evidence from marketing channels in China, Industrial Marketing Management, 40 (2011) 503-509.

[26] T.A. Brunner, M. Stöcklin, K. Opwis, Satisfaction, image and loyalty: new versus experienced customers, European journal of marketing, 42 (2008) 1095-1105.

[27] J.Y. Park, K. Park, A.J. Dubinsky, Impact of retailer image on private brand attitude: Halo effect and summary construct, Australian Journal of Psychology, 63 (2011) 173-183.

[28] M. Sääksjärvi, S. Samiee, Relationships among brand identity, brand image and brand preference: differences between cyber and extension retail brands over time, Journal of interactive marketing, 25 (2011) 169-177.
[29] Y. Bao, Y. Bao, S. Sheng, Motivating purchase of private brands: Effects of store image, product signatureness, and quality variation, Journal of Business Research, 64 (2011) 220226.

[30] M. Heinberg, H.E. Ozkaya, M. Taube, Do corporate image and reputation drive brand equity in India and China?Similarities and differences, Journal of Business Research, DOI (2017).

[31] M.A. Jones, D.L. Mothersbaugh, S.E. Beatty, Switching barriers and repurchase intentions in services, Journal of retailing, 76 (2000) 259-274.

[32] J.S.-C. Hsu, Understanding the role of satisfaction in the formation of perceived switching value, Decision Support Systems, 59 (2014) 152-162.

[33] A. Picón, I. Castro, J.L. Roldán, The relationship between satisfaction and loyalty: A mediator analysis, Journal of Business Research, 67 (2014) 746-751.

[34] N. Bendapudi, L.L. Berry, Customers' motivations for maintaining relationships with service providers, Journal of retailing, 73 (1997) 15-37.

[35] L.-B. Oh, H.-H. Teo, V. Sambamurthy, The effects of retail channel integration through the use of information technologies on firm performance, Journal of Operations Management, 30 (2012) 368-381.

[36] O. Emrich, M. Paul, T. Rudolph, Shopping Benefits of Multichannel Assortment Integration and the Moderating Role of Retailer Type, Journal of Retailing, 91 (2015) 326-342.

[37] S. Saghiri, R. Wilding, C. Mena, M. Bourlakis, Toward a three-dimensional framework for omni-channel, Journal of Business Research, 77 (2017) 53-67.

[38] H. Schramm-Klein, G. Wagner, S. Steinmann, D. Morschett, Cross-channel integration - is it valued by customers?, The International Review of Retail, Distribution and Consumer Research, 21 (2011) 501-511.

[39] J. van Doorn, M. Onrust, P.C. Verhoef, M.S. Bügel, The impact of corporate social responsibility on customer attitudes and retention - the moderating role of brand success indicators, Marketing Letters, 28 (2017) 607-619.

[40] B. Akdeniz, R.J. Calantone, C.M. Voorhees, Effectiveness of marketing cues on consumer perceptions of quality: The moderating roles of brand reputation and third-party information, Psychology \& Marketing, 30 (2013) 76-89.

[41] H. Hansen, B.M. Samuelsen, J.E. Sallis, The moderating effects of need for cognition on drivers of customer loyalty, European Journal of Marketing, 47 (2013) 1157-1176.

[42] C. Antón, C. Camarero, M. Carrero, Analysing firms' failures as determinants of consumer switching intentions: The effect of moderating factors, European Journal of Marketing, 41 (2007) 135-158.

[43] J. Bojei, C.C. Julian, C.A.B.C. Wel, Z.U. Ahmed, The empirical link between relationship marketing tools and consumer retention in retail marketing, Journal of Consumer Behaviour, 12 (2013) 171-181.

[44] J.J. Heckman, Sample Selection Bias as a Specification Error, Econometrica, 47 (1979) 153-161.

[45] M. Blut, S.E. Beatty, H. Evanschitzky, C. Brock, The impact of service characteristics on the switching costscustomer loyalty link, Journal of Retailing, 90 (2014) 275-290. 